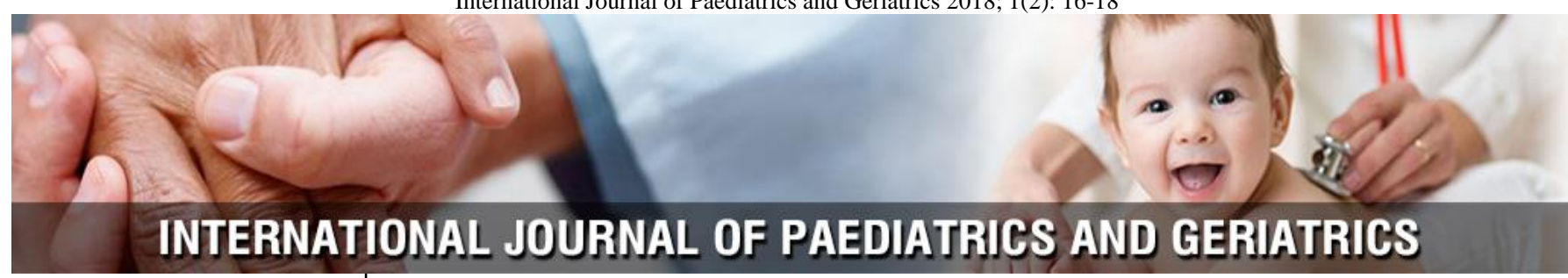

P-ISSN: 2664-3685

E-ISSN: 2664-3693

www.paediatricjournal.com IJPG 2018; 1(2): 16-18

Received: 24-05-2018

Accepted: 27-06-2018

Dr. Suresh Babu

Department of Paediatrics, KPC Medical College and

Hospital, Kolkata, West

Bengal, India
Corresponding Author: Dr. Suresh Babu Department of Paediatrics, KPC Medical College and Hospital, Kolkata, West Bengal, India

\title{
Assessment of celiac disease and their effects on quality of life in children: A clinical study
}

\section{Dr. Suresh Babu}

DOI: https://doi.org/10.33545/26643685.2018.v1.i2a.15

\begin{abstract}
Background: Celiac disease (CD), an immune-mediated systemic disorder. The present study was conducted to assess celiac disease and their effects on quality of life in children.

Materials \& Methods: The present study was conducted on 43 children age ranged 6-15 years of age with celiac disease. Equal numbers of controls were selected. Quality of life was assessed using PedsQL 4.0, with 23-item multidimensional generic core scales. Raw scores were assessed based on a 5 -point Likert scale $(0=$ never a problem; $1=$ almost never a problem; $2=$ sometimes a problem; $4=$ almost always a problem), which was reverse-scored and linearly transformed to a $0-100$ scale $(0=$ $100,1=75,2=50,3=25,4=0$ ), with higher scores indicating better HRQoL.

Results: Age group 6-7 years had 4 males and 6 females, 8-9 years had 5 males and 4 females, 10-11 years had 3 males and 6 females, 12-13 years had 3 males and females and 14-15 years had 5 males and 4 females. The mean PedsQL score in celiac group was 72.4 and in control group was 80.2, state anxiety score was 35.2 in celiac group and 32.4 in control group, trait anxiety score was 34.1 and 30.9 in celiac and control group respectively. Depression score was 14.2 and 10.5 in celiac and control group respectively. The difference was significant $(P<0.05)$.

Conclusion: Authors found that there was significant difference in quality of life of celiac and normal children.
\end{abstract}

Keywords: Celiac disease, Children, Gluten

\section{Introduction}

Celiac disease (CD), an immune-mediated systemic disorder in genetically predisposed individuals initiates through the ingestion of gluten and related prolamins such as cereals (wheat, rye, and barley) containing gluten, a protein complex ${ }^{[1]}$. The overall global prevalence of $\mathrm{CD}$ is estimated to be $1 \%$, but it varies depending on age and country of origin of the study population. Furthermore, many researchers acknowledge that the current prevalence of the disease may be underestimated due to under diagnosis ${ }^{[2]}$.

Children, especially if they are ill, can show very intense emotional reactions. This can affect their social functioning because of their feelings of shame; children can avoid contacts and having meals with others and, on the other hand, their peers sometimes may have a problem in social acceptance of celiac patients ${ }^{[3]}$.

The basis of the disease and the key finding in its diagnostics is gluten-sensitive enteropathy, i.e. a nonspecific inflammation of the small intestinal mucosa that resolves by gluten-free diet ${ }^{[4]}$. Besides enteropathy, either symptomatic or asymptomatic, the disease is also characterized by different extra intestinal manifestations, as well as potentially severe complications. As it is disclosed in only 1:5-13 cases, today celiac disease is ranked as the most frequent chronic disease of the modern man ${ }^{[5]}$ The present study was conducted to assess celiac disease and their effects on quality of life in children.

\section{Materials \& Methods}

The present study was conducted in the department of pediatrics. It comprised of 43 children age ranged 6-15 years of age with celiac disease. Equal numbers of controls were selected. The study protocol was approved from ethical committee. Parents were informed regarding the study and written consent was obtained.

Data such as name, age, gender etc. was recorded. A thorough clinical examination was done in all patients. Quality of life was assessed using Peds QL 4.0, with 23-item multidimensional generic core scales. Raw scores were assessed based on a 5-point Likert scale $(0=$ never a problem; $1=$ almost never a problem; $2=$ sometimes a problem; $4=$ almost always a problem), which was reverse-scored and linearly transformed to a 0-100 scale 
$(0=100,1=75,2=50,3=25,4=0)$, with higher scores indicating better HRQoL. Results were subjected to statistical analysis. $\mathrm{P}$ value less than 0.05 was considered significant.

\section{Results}

Table I: Distribution of patients

\begin{tabular}{|c|c|c|}
\hline Age group (Years) & Males & Females \\
\hline $6-7$ & 4 & 6 \\
\hline $8-9$ & 5 & 4 \\
\hline $10-11$ & 3 & 6 \\
\hline $12-13$ & 3 & 3 \\
\hline $14-15$ & 5 & 4 \\
\hline Total & 20 & 23 \\
\hline
\end{tabular}

Table I shows that age group 6-7 years had 4 males and 6 females, 8-9 years had 5 males and 4 females, 10-11 years had 3 males and 6 females, 12-13 years had 3 males and females and 14-15 years had 5 males and 4 females.

Table 2: Assessment of Quality of life

\begin{tabular}{|c|c|c|c|}
\hline Scores & Coelic group & Control & P value \\
\hline Peds QL & 72.4 & 80.2 & 0.01 \\
\hline State anxiety score & 35.2 & 32.4 & 0.02 \\
\hline Trait anxiety score & 34.1 & 30.9 & 0.04 \\
\hline Depression score & 14.2 & 10.5 & 0.001 \\
\hline
\end{tabular}

Table II, graph I shows that mean Peds QL score in celiac group was 72.4 and in control group was 80.2 , state anxiety score was 35.2 in celiac group and 32.4 in control group, trait anxiety score was 34.1 and 30.9 in celiac and control group respectively. Depression score was 14.2 and 10.5 in celiac and control group respectively. The difference was significant $(\mathrm{P}<0.05)$.

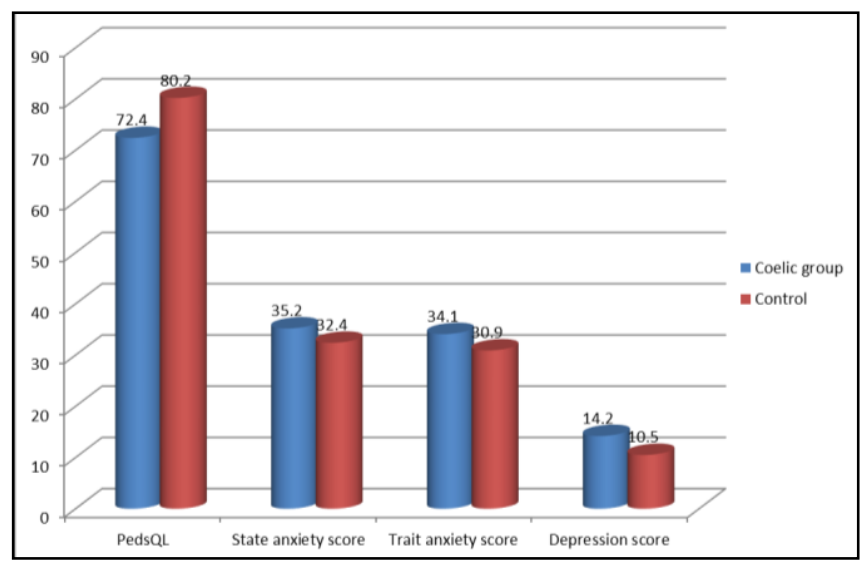

Graph 1: Quality of life

\section{Discussion}

Celiac disease belongs to the group of chronic inflammatory diseases of multifactorial nature. Beside polygenic predisposition and exposure to gluten as the trigger of autoimmune process, some other factors also have essential participation in the expression of the disease, such as too early ( $<17$ weeks) or too late ( $\geq 26$ weeks), introduction of gluten into the child's diet, absent breastfeeding at that time, rotavirus gastroenteritis and other. ${ }^{6}$ HLA class II genes play a central role in the hereditary predisposition to the disease, but also with the unavoidable participation of other genetic loci. $^{7}$ The present study was conducted to assess celiac disease and their effects on quality of life in children.

In this study, age group 6-7 years had 4 males and 6 females, 8-9 years had 5 males and 4 females, 10-11 years had 3 males and 6 females, 12-13 years had 3 males and females and 14-15 years had 5 males and 4 females.

Stevanović et al ${ }^{[8]}$ included 116 respondents aged 5-18 years with celiac disease and 116 healthy children of similar age and gender. A Serbian version of Paediatric Quality of Life Inventory (Peds QL) was used as an instrument for measuring of quality of life in children. The mean value of total Peds QL score was lower in the celiac disease patients $(75.89 \pm 20.35)$ than in the controls $(86.35 \pm 11.13)$. Additionally, the experimental group reported lower all Peds QL Scale scores than the control group in the domains of psychosocial, school, social and emotional functioning. However, there was no statistically significant difference on the physical health scale. These results were the same in all age groups among both males and females.

We observed that mean Peds QL score in coelic group was 72.4 and in control group was 80.2 , state anxiety score was 35.2 in celiac group and 32.4 in control group, trait anxiety score was 34.1 and 30.9 in celiac and control group respectively. Depression score was 14.2 and 10.5 in celiac and control group respectively. The difference was significant $(\mathrm{P}<0.05)$.

Wagner et $a l^{[9]}$ conducted a cross-sectional study was done between 2013 and 2014 at the Gastroenterology Outpatient Clinic in patients with serology and biopsy-proven $\mathrm{CD}$, on a gluten-free diet for at least one year and compared with nonceliac healthy children as controls. There were statistically significant differences between the mean total anxiety (state, trait) scores and depression score in the celiac patients and control group. Correlations between state and trait anxiety and depression were statistically significant $(\mathrm{P}=0.01, \mathrm{r}=$ $0.35)$ and $(\mathrm{P}=0.001, \mathrm{r}=0.52)$. Reverse correlations between quality of life of $\mathrm{CD}$ children and anxiety (state, trait) were statistically significant $(\mathrm{P}=0.001, \mathrm{r}=0.51$ and $\mathrm{P}=0.02, \mathrm{r}=$ 0.32 ). Mean total score of quality of life was not different in the two groups, but in the physical activity component, quality of life was better in CD patients.

\section{Conclusion}

Authors found that there was significant difference in quality of life of Coelic and normal children.

\section{References}

1. Simeoni MC, Auquier P, Antoniotti S, Sapin C, San Marco JL. Validation of a French health- related qualityof life instrument for adolescents: the VSP-A. Qual Life Res. 2000; 9(4):393-403.

2. Di Filippo T, Orlando MF, Concialdi G, La Grutta S, Lo Baido R, Epifanio MS et al. The quality of life in developing age children with celiac disease. Minerva Pediatr. 2013; 65(6): 599-608.

3. Tapsas D, Fälth-Magnusson K, Högberg L, Hammersjö JÅ, Hollén E. Swedish children with celiac disease comply well with a gluten-free diet, and most include oats without reporting any adverse effects: a long-term follow-up study. Nutr Res. 2014; 34: 436-441.

4. Varni JW, Seid MD, Kurtin PS. Peds QL. Reliability and validity of the Pediatric Quality of Life Inventory ${ }^{\mathrm{TM}}$ Version 4.0 Generic Core Scales (PedsQL ${ }^{\mathrm{TM}}$ ) in the general Serbian population. Qual Life Res 2011; 20:945-9. 
5. Sevinç E, Çetin FH, Coşkun BD. Psychopathology, quality of life, and related factors in children with celiac disease. J Pediatr (Rio J). 2017; 93(3):267-73.

6. Ciacci C, Iavarone A, Siniscalchi M, Romano R, De Rosa A. Psychological dimensions of celiac disease: towards an integrated approach. Dig Dis Sci 2002; 47:2082-7.

7. Zarkadas M. Living with celiac disease and a glutenfree diet: A Canadian perspective. J Hum Nutr Diet. 2013; 26:10-23.

8. Stevanović D, Lakić A, Damnjanović M. Some psychometric properties of the Pediatric Quality of Life Inventory ${ }^{\mathrm{TM}}$ Version 4.0 Generic Core Scales (PedsQL ${ }^{\mathrm{TM}}$ ) in the general Serbian population. Qual Life Res 2011; 20: 945-9.

9. Wagner G, Berger G, Sinnreich U, Grylli V, Schober E, Huber WD et al. Quality of life in adolescents with treated coeliac disease: Influence of compliance and age at diagnosis. J Pediatr Gastroenterol Nutr 2008; 47:555-61. 